\title{
Experimental and numerical study of a vertical axis tidal turbine performance
}

\author{
Shahram Derakhshan ${ }^{1}$, Mohammadreza Ashoori, Amirhosein Salemi \\ School of Mechanical Engineering, Iran University of Science \& Technology, Narmak 16846, Tehran, \\ Iran
}

\begin{abstract}
In the present study, a vertical axis tidal turbine with movable blades was investigated using experimental and numerical methods. A laboratory model of this turbine type nominated as Hunter turbine was manufactured and tested in an established test rig. In the next step, 3D steady Reynolds-Averaged NavierStokes (RANS) equations were solved by CFD using k- $\omega$ turbulence model to predict turbine's performance. The numerical results were verified by the experimental data. In addition, effects of duct, neighbor turbines distance and layout on the power coefficient were investigated. The results showed that the power coefficient of a turbine in the present of ducts with area ratios of 0.1 to 0.26 increased from 0.14 to 0.29 . It was also observed that in a four-turbine farm, the output power is maximum for a distance of $13 D$ (diameter of turbine) between neighbor turbines and area ratio of 0.26 . For this case, the farm's performance factor is 0.944 .
\end{abstract}

Keywords: Tidal turbine; Power coefficient; Duct; Farm performance factor.

${ }^{1}$ Corresponding author. Tel: +98 (21) 77240206; Fax: +98 (21) 73021614

E-mail address: shderakhshan@iust.ac.ir

\section{Introduction}

(C) 2017. This manuscript version is made available under the Elsevier user license http://www.elsevier.com/open-access/userlicense/1.0/ 
Recently, due to the growing concerns about pollution from energy sources that come from fossil fuels such as oil, coal and natural gas, there have been some reasonable effective efforts in international agreements and national energy action plans, such as EU 2009 Renewable Energy Directive to increase the use of renewable energy [1-2]. Clean energies are going to be important by considering environmental limitations such as greenhouse gases and earth warming problem. Off grid renewable energies such as solar energy, wind power energy, hydro energy, and biomass energy are the main alternative to overcome the mentioned problems. Unfortunately, renewable energies are not always economical in comparison with the conventional energies. Therefore, designing the low-cost machines with higher efficiencies is a hot topic for researchers and engineers [3]. Marine energy, also known as ocean energy and marine hydrokinetic energy including tidal and wave powers, is a relatively new sector of renewable energy. The theoretical annual potential is equivalent to $4 \sim 18$ million tones oil equivalent (toe per year). International development of marine energy are currently doing by advanced technologies such as wave energy converters in open coastal areas with significant waves, tidal turbines placed in coastal and estuarine areas, stream turbines in fast-moving rivers, ocean current turbines in areas of strong marine currents and ocean thermal energy converters in deep tropical waters [4].

Some researchers have worked on applying advanced technologies to convert available hydro potentials in water systems [5-10] by pumps used as turbines [11-13]. In addition, micro-hydro turbines were applied to recover rivers flow potential vastly [3, 14-18]. For ocean wave energy, sea- wave generators used for wave energy recovery [19,20].

Tidal turbines are interested in coastal area with reasonable tides. Two types of turbines are usually implied to produce the energy from tides: Horizontal axis and vertical axis [21-23]. One of the axial turbines with movable blades named as Hunter turbine was investigated by Yang and Lawn [24,25]. They analyzed the performance of this turbine in a stand-alone application comparing with fix blades turbines. They reported that this turbine is more efficient than conventional vertical fixed blades turbines. 
Vennell [26] and $\mathrm{Li}$ [27] considered the performance factor of tidal turbines in a farm. Garret and Cummins [28] studied the maximum output power of a channel from an oceanography point of view by treating the turbine as a black box and the channel as a two dimensional flow with lateral boundary. Whelan et al. [29] studied the maximum output power of a channel by treating the channel as a two dimensional flow with vertical boundary.

In the present study, a model of Hunter turbine was carefully manufactured to test in an established test rig in laboratory of IUST. The turbine had six movable blades hinged around a cylinder with aspect ratio of 1.0. Measured data was used to verify the numerical simulation data done by flow solver. This verified numerical model was applied to consider the effects of the duct and the farm (multi-tidal turbines) on the performance of the turbine. Finally, results was considered and discussed.

\section{Case study}

The model of vertical axis tidal turbine with six movable blades around a cylindrical casing with an aspect ratio of 1.0 was selected to analyse experimentally and numerically. The turbine includes a long main shaft, six small shafts for blades installation, a cylindrical body and six blades. Fig.1 illustrates the model of this turbine. The diameter and the height of this turbine were $0.6 \mathrm{~m}$.

\section{Experimental setup}

A complete open test rig was constructed in laboratory for testing the model of turbine. Fig.2 shows the turbine's position in an open channel. Water flow was provided by a centrifugal pump type KSB-100250. Using pump's characteristic curve, after measuring the pump head using barometer (ranged 0 to 1.0 bar), the flow discharge was obtained. Using the value of discharge, the velocity of flow has been 
determined. To measure the power, after obtaining the rotational speed by a laser tachometer, the shaft torque was measured by a dynamometer.

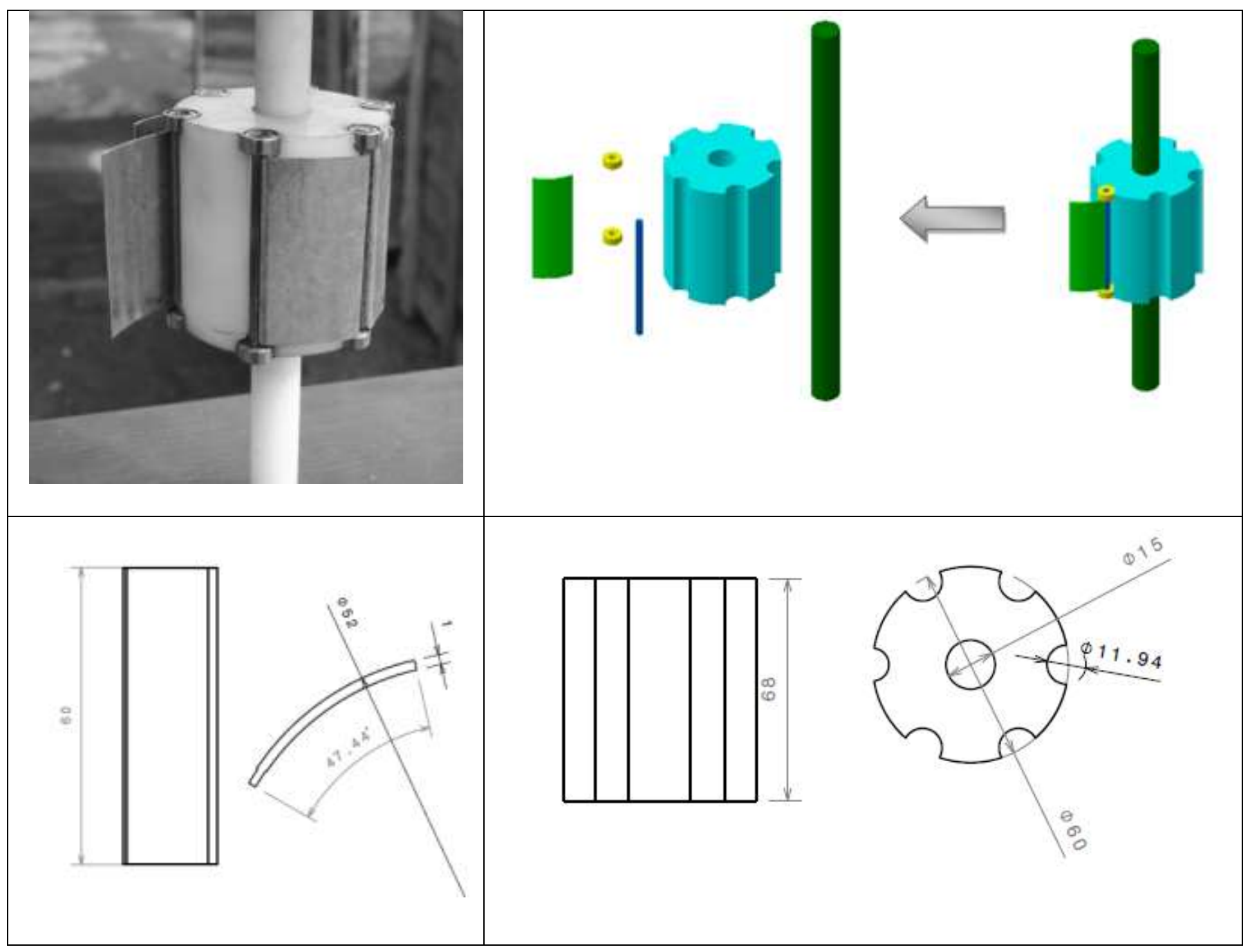

Fig.1. Laboratory model of vertical axis tidal turbine

Using measured data, the flow coefficient was obtained using:

$C_{f}=\frac{\omega R_{c}}{U}$

where $\omega$ is the angular velocity, $U$ is the flow velocity and $R_{\mathrm{c}}$ is the distance between the drum axis and the center of the blade chord when the blade is completely opended. And the power coefficient of turbine was derived by: 
$C_{\text {Pow }}=\frac{P}{1 / 2 \rho A U^{3}}$

where $\rho, A$ and $U$ denote the water density, the section area of the turbine and the inlet flow velocity, respectively.

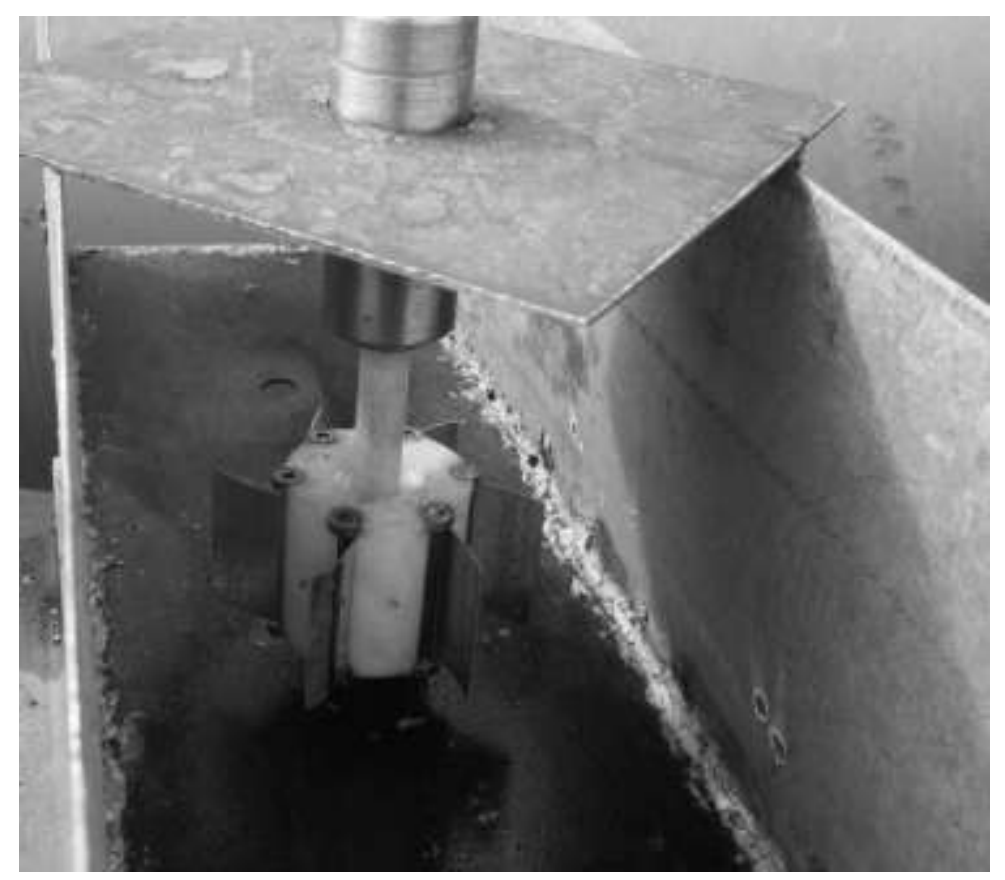

Fig.2. Turbine position in open channel test rig

\section{Numerical setup}

ANSYS CFX is a RANS (Reynolds Average Navier-Stokes) solver. It is a fully-implicit flow solver, creates a no time step limitation considered easy to implement. It is also a coupled flow solver meaning that the momentum and continuity equations are solved simultaneously. This approach reduces the number of iterations required to obtain convergence criteria and no pressure correction term is required to retain mass conservation, leading to a more robust and accurate solver [30].

The discretization method for solving the problem was first order upwind. Yang proved that $k-\omega$ model is suitable for a flow field simulation with a high angle of attack [31]. Therefore, $k$ - $\omega$ turbulence model was selected to estimate the Reynolds stresses of RANS equations. 
After creating the geometry in CADCAM, it's necessary to generate grids for the computational domain shown in Fig.3. An unstructured grids, tetrahedral cells type, were used to discrete the computational domain. The number of cells were more near the turbine by violent changes in the flow regime. To invetsigate the flow solveing results grid indipendency, the turbine torque was used as a boundary parameter to evaluate the effect of cells number on results. It was founded that for cells number over than 1.200.000, the turbine torque is approximately fixed.

Table 1 shows the boundary conditions for the computational domain of the flow around the turbine. 3D steady state equations was solved for water at $20^{\circ} \mathrm{C}$ around the wall with $50 \mu \mathrm{m}$ roughness.

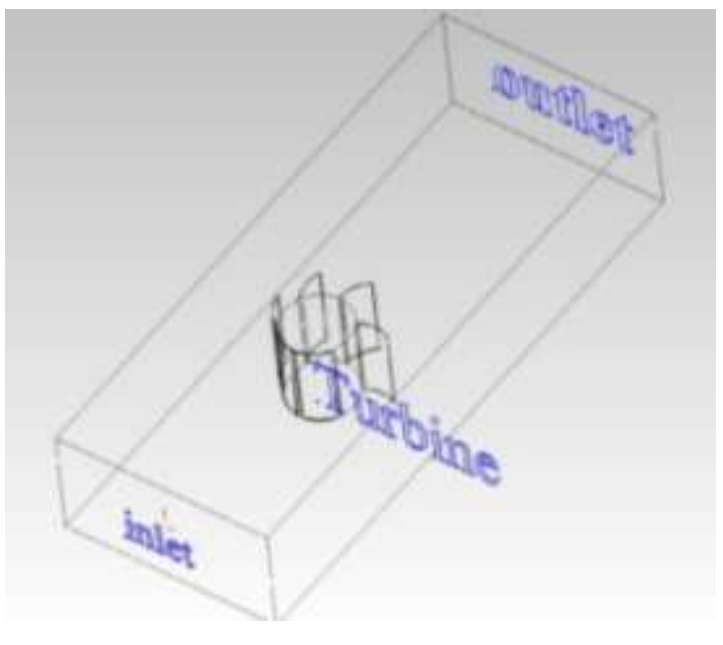

a

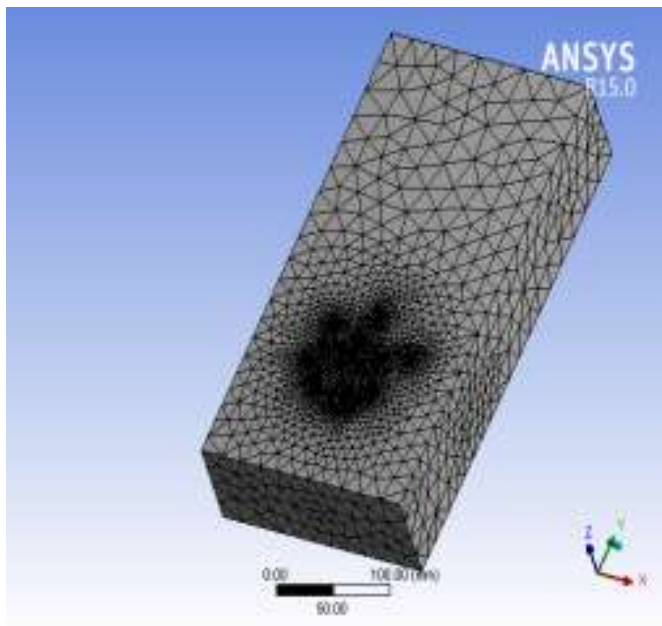

b

Fig.3. a) Computational domain of turbine b) Unstructured grids of turbine

Table 1. Boundary conditions of the computational domain

Inlet

Outlet

Left \& right surfaces

Turbine

Lower surface

Upper surface
Normal speed: $1.023 \mathrm{~m} / \mathrm{s}$

Avg. relative static pressure: $0 \mathrm{~Pa}$

Wall

Rotating wall: $10.47 \mathrm{rad} / \mathrm{s}$

Wall

Opening 


\section{Results and discussion}

\subsection{Stand-alone turbine's performance}

In order to ensure the solutions, the results of the numerical simulations of a stand-alone turbine, were compared with the experimental data. The flow around the turbine were numerically investigated at 5 flow coefficients corresponding to 5 inlet velocites. The considered flow coefficients were $0.29,0.36$, $0.45,0.53$ and 0.56 .

At flow coefficients of 0.53 and 0.56 , the flow velocities were $1.2 \mathrm{~m} / \mathrm{s}$ and $1.4 \mathrm{~m} / \mathrm{s}$, respectevely. Which in these cases, the flow was more turbulent and the turbine could not absorb the energy of the flow well. Therefore, power losses were more. In addition, the water level was lower than the upper surface of the turbine and the turbine wasn't completely submerged.

The power coefficient derived from the numerical method for the flow coefficient of 0.45 was 0.20 and the power coefficient calculated from the experimental data was 0.19 (Fig.4). The maximum deviation of the numerical results from the experimental data for the flow coefficient was $4 \%$. All calculations were done for the flow coefficient of 0.45 to achieve a maximum power coefficient (inlet uniform velocity of $1 \mathrm{~m} / \mathrm{s}$ and angular velocity of $100 \mathrm{rpm}$ ).

Fig. 5 shows the velocity contours of the flow in six different angles of rotation in the flow coefficient of 0.45 . The velocity suddenly decrease in downstream. The low velocity area in blade angles of 0 and 50 are more than the other blade angles. Fig.6 can help to clarify the issue. Pressure distribution for angles between 0 and 50 have a low back pressure. This phenomenon leads to a wake flow shown in Fig.7 for various angles. 


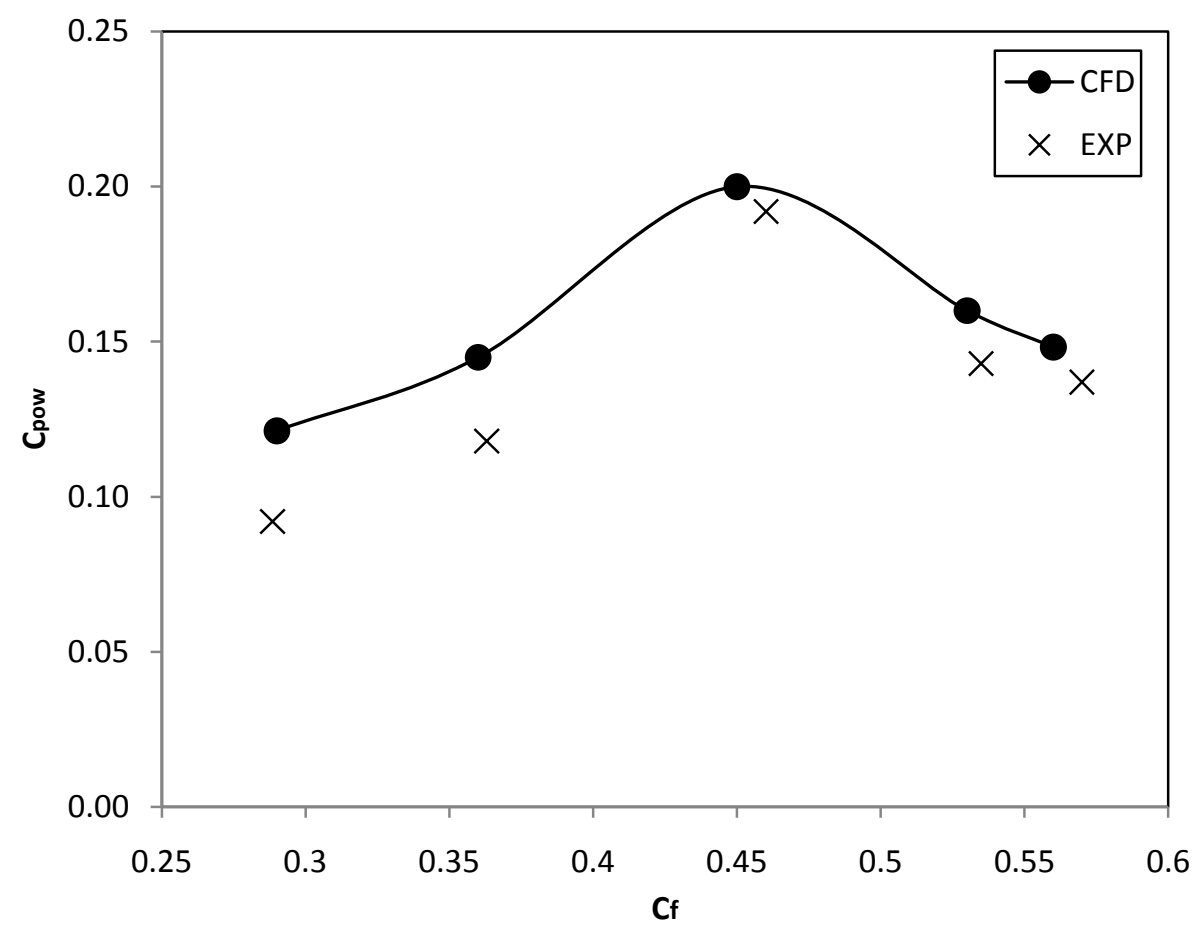

Fig.4. Comparison of the experimental and the numerical results for the power coefficients
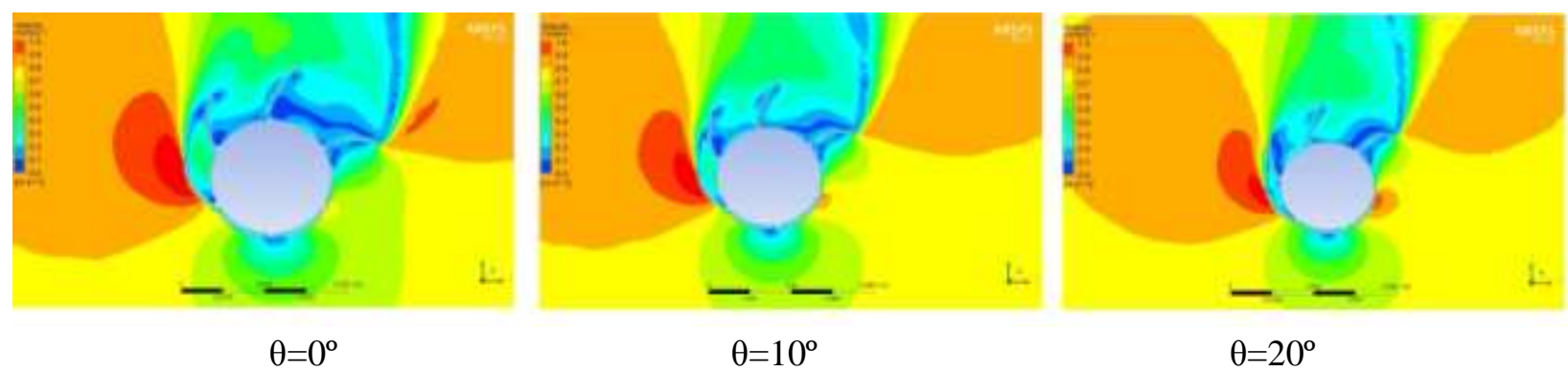

$\theta=20^{\circ}$
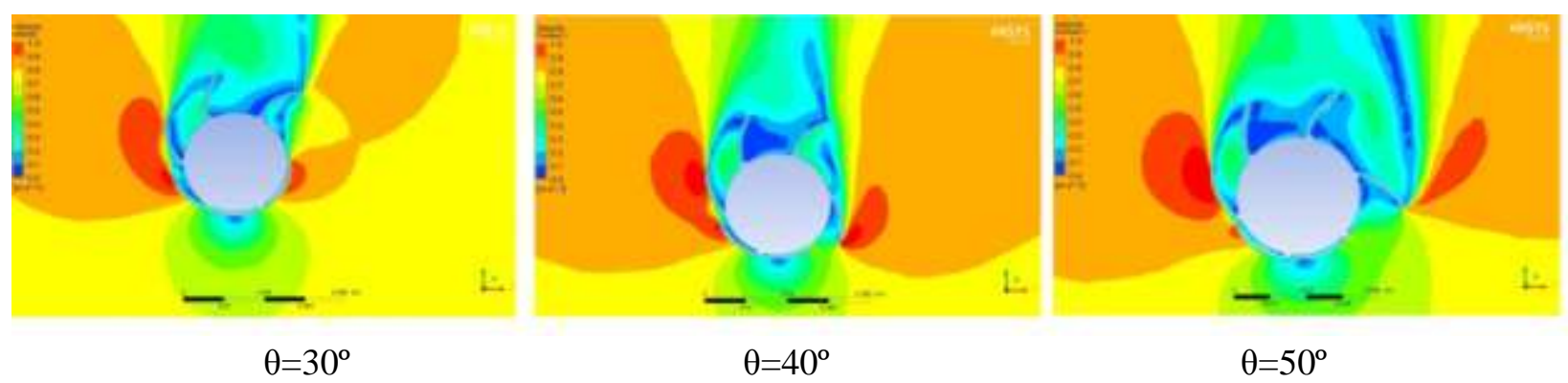

Fig.5. Velocity counters in different blade angles at $\varphi=0.45$ 

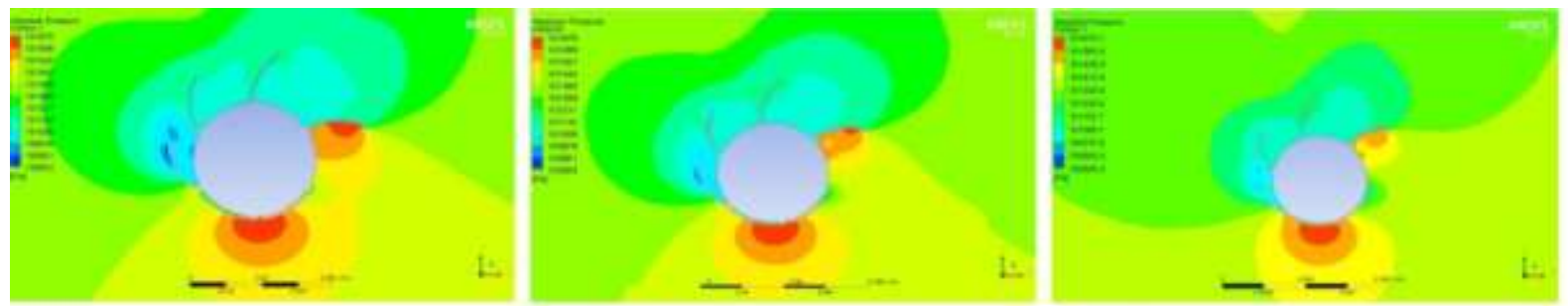

$\theta=0^{\circ}$

$\theta=10^{\circ}$

$\theta=20^{\circ}$
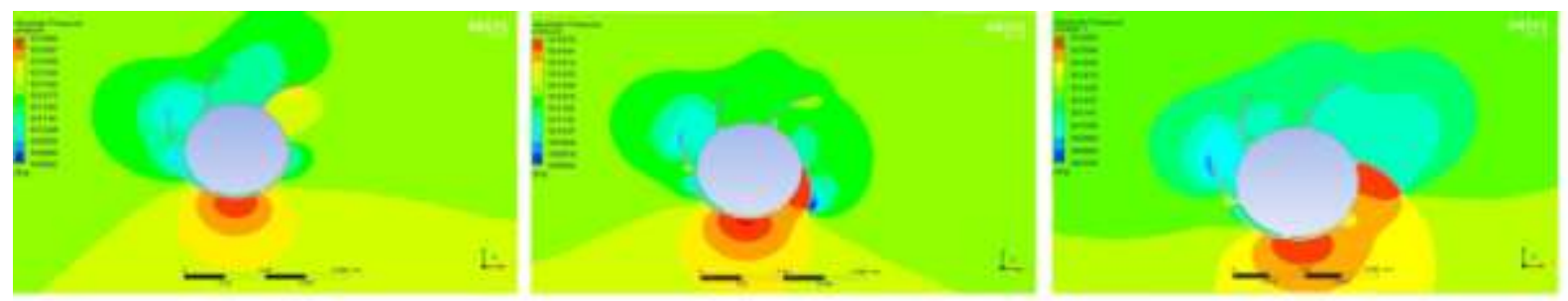

$\theta=30^{\circ}$

$\theta=40^{\circ}$

$\theta=50^{\circ}$

Fig.6. Pressure counters in different blade angles at $\varphi=0.45$
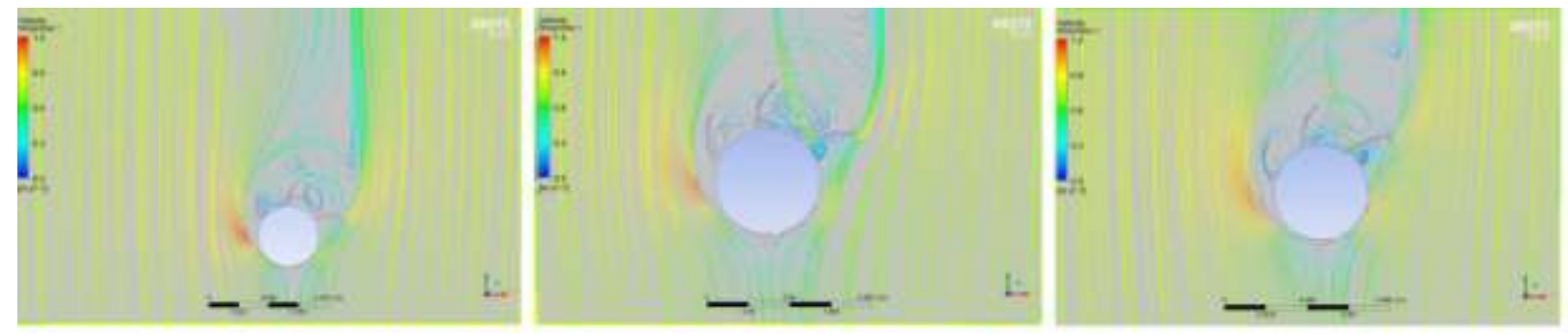

$\theta=0^{\circ}$

$\theta=10^{\circ}$

$\theta=20^{\circ}$
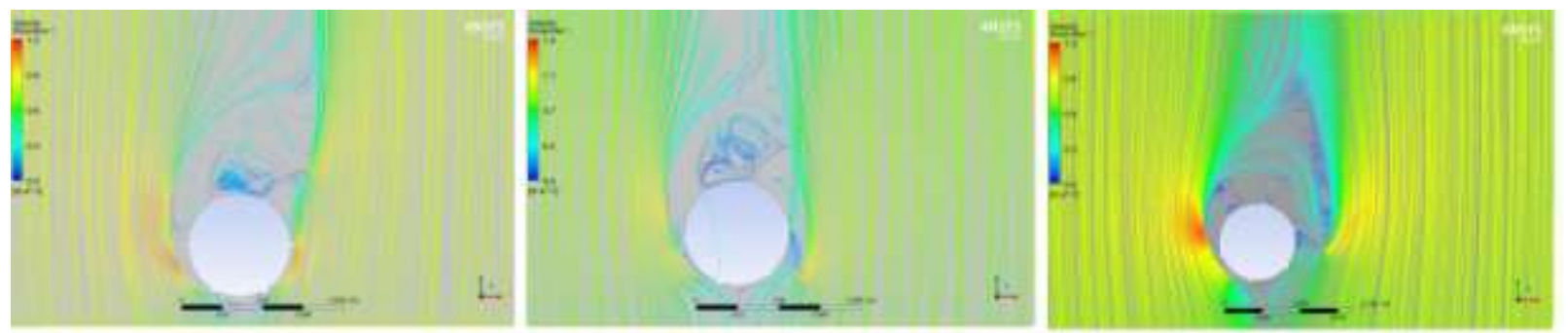

$\theta=30^{\circ}$

$\theta=40^{\circ}$

$\theta=50^{\circ}$

Fig.7. Stream lines in different blade angles at $\varphi=0.45$ 


\subsection{Turbine's performance in duct}

In this step, we considered a turbine placed in various ducts with different dimensions (Fig.8). Table 2 presents the power coefficients (Eq. (2)) of ducts in different cross sections and area rations according to Fig. 8. It can be seen that the duct No.3, though very narrow, has a high power coefficient two times more than the power coefficient of case No.1 and 1.56 times more than the power coefficient of case No.2. Therefore, the power coefficient of the turbine increases up to 0.29 due to existence of the duct. In conclusion, when the wall is closer to the turbines, the flow will cause to product the power effectively and more suitably.

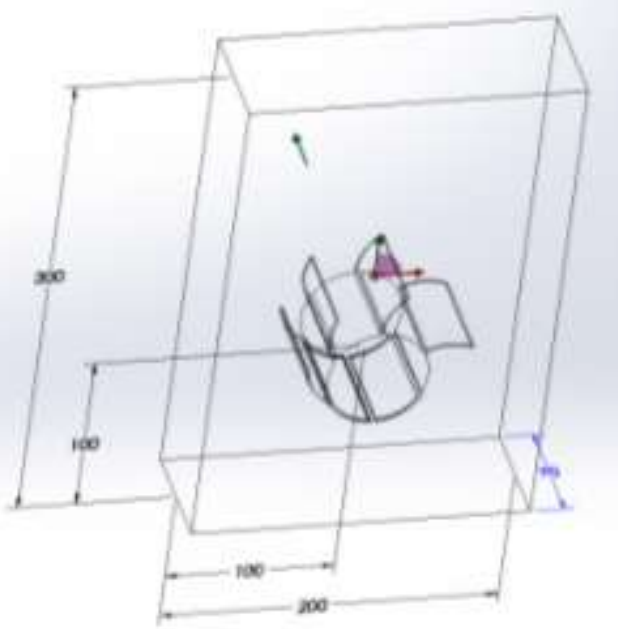

a

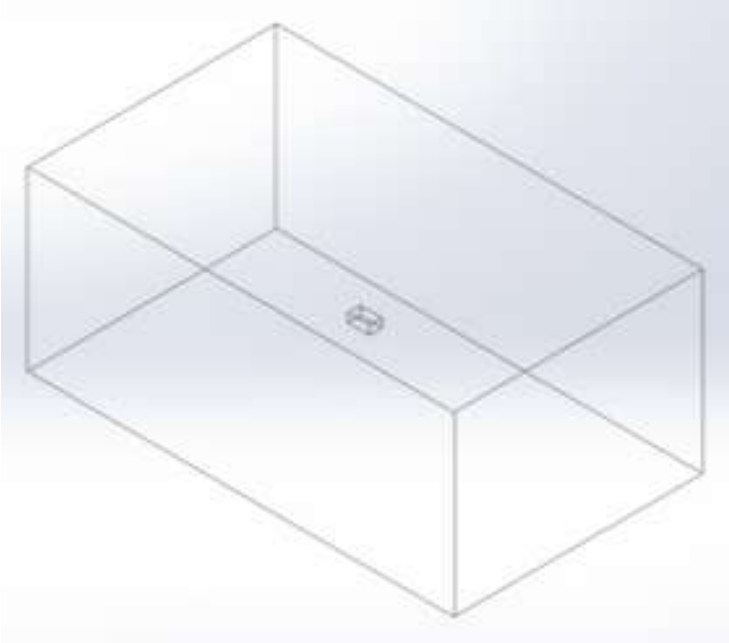

b

Fig.8. a) Dimension of duct and the position of turbine (case No.3) b) computational domain around the duct

Table 2. Cross section of ducts and corresponding power of coefficients

\begin{tabular}{cccc}
\hline Case No. & Cross section of duct & Area ratio & $\mathrm{C}_{\text {pow }}$ \\
\hline 1 & $300 \times 120$ & 0.1 & 0.15 \\
2 & $200 \times 100$ & 0.18 & 0.19 \\
3 & $200 \times 70$ & 0.26 & 0.29 \\
\hline
\end{tabular}




\subsection{Turbines' performance in farm}

An important object in designing of a farm is to maximize the total output power. For a stand-alone turbine, the displacement of the turbine is not critical. However, due to the nature of the operational conditions and the need for cost-effective power plants, the construction scheme for a tidal currentturbine farm is expected to have turbines installed closely. When these turbines are very close to each other, there are a hydrodynamic interaction affecting the performance of each turbine. Here, similar to the stand-alone turbine's power coefficient, we can define a farm's performance factor, $k$, as:

$k=\frac{P_{\text {farm }}}{P_{\text {ref }, \text { farm }}}=\frac{\sum_{i=1}^{N} P_{i}}{N \times P_{S}}$

where $P_{\mathrm{s}}$ denotes the output power from the corresponding stand-alone turbine, $P_{\mathrm{i}}$ denotes the output power of the turbine number $i$, and $P_{\text {ref,farm }}$ denotes the reference output power of the farm at the given operational condition. All output power's variables represent the mean output power under optimal conditions, i.e., the maximum mean output power. Particularly, $P_{\text {ref,farm }}$ does not only represent a summation of the output power of $N$ number of stand-alone turbines, but also, more practically, it represents the output power of the farm with non-hydrodynamics interaction between the turbines [27]. In fact, in a reference farm, two neighbor turbines are installed in a position without any hydrodynamics iteration. However, a farm is practically selected with internal hydrodynamics effects (because of extra limitations i.e. economic and environmental issues).

In this part, the distance of turbines from each other and the impact of the cross-section of the duct on the performance factor were analyzed (Fig.9). Although, the area was occupied by the turbine changes at different blades openings, the reference area can be considered equal to the turbine's diameter and height. Area ratio defines as: 


$$
A_{r}=\frac{\text { Diameter } \times \text { Height }}{\text { cross section area }}
$$

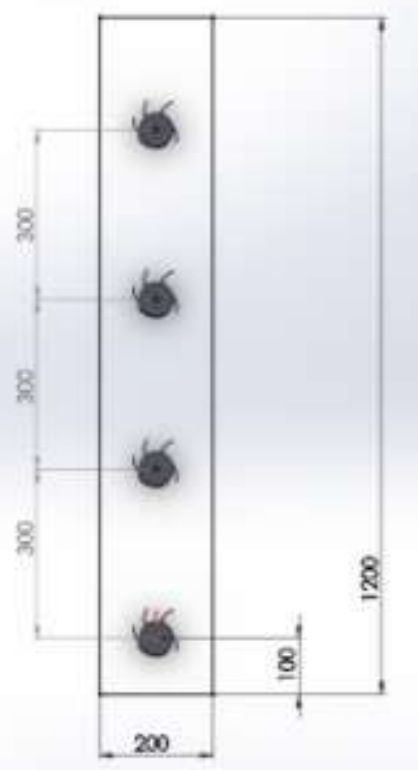

Fig.9. A four array of consecutive turbines

The distance of turbines from each other and its impact on the farm performance's factor with 2, 3 and 4 consecutive turbines were reported in table 3. Farm efficiencies reached to its optimal values at the distance of $13 D$ (13 times of turbine's diameter), $15 D$ and $5 D$ for 2,3 and 4 consecutive turbines, respectively. It concluded that the efficiency of each farm with different number of turbines is optimal at different distances. However, turbines installed at the distance of $15 D$ are far away and it is imagined that the effect of downstream turbine neutralized with its upstream turbine. According to table 3 , the farm efficiency of 4 consecutive turbines reached to 1 that is very remarkable. Fig. 10 shows the velocity contours for two consecutive turbines placed in a duct with area ratio of 0.26 . When the distance of two turbines is $5 D$, the wake of the upstream turbine effects on the inlet flow of the downstream turbine with a lower velocity. This will dramatically reduce the power and the efficiency of two consecutive turbines. But it's necessary to mention that the maximum farm's efficiency of four consecutive turbines happens at an optimum distance of $5 D$. 
As shown in table 4 , by increasing the area ratio from 0.1 to 0.26 , the farm performance factor rises about $8 \%, 10 \%$ and $11 \%$ for 2,3 and 4 turbines, respectively.

Table 3. Effect of turbine distance on the farm performance factor for $2,3 \& 4$ consecutive turbines at the area ratio of 0.26

\begin{tabular}{cccc}
\hline Distance & $\mathrm{k}_{2 \text { turbines }}$ & $\mathrm{k}_{3 \text { turbines }}$ & $\mathrm{k}_{4 \text { turbines }}$ \\
\hline $5 \mathrm{D}$ & 0.881 & 0.821 & 1.00 \\
$10 \mathrm{D}$ & 0.954 & 0.951 & 0.926 \\
$\approx 13 \mathrm{D}$ & 0.971 & 0.961 & 0.954 \\
$15 \mathrm{D}$ & 0.967 & 0.963 & 0.944 \\
\hline
\end{tabular}

Table 4. Effect of area ratio on the farm performance factor for $2,3 \& 4$ consecutive turbines at the distance of 13D

\begin{tabular}{cccc}
\hline Area ratio & $\mathrm{k}_{2 \text { turbines }}$ & $\mathrm{k}_{3}$ turbines & $\mathrm{k}_{4}$ turbines \\
\hline 0.1 & 0.905 & 0.892 & 0.867 \\
0.18 & 0.954 & 0.940 & 0.922 \\
0.26 & 0.967 & 0.963 & 0.944 \\
\hline
\end{tabular}

Fig. 11 shows the velocity contours for two consecutive turbines in the distance of $13 D$ within different area ratios. The flow regime in downstream turbine is almost similar to the upstream turbine. Therefore, the distance of turbines is long sufficiently to prevent any impact on each other. However, the velocity reaches to $1.6 \mathrm{~m} / \mathrm{s}$ at some places for an area ratio of 0.1 and increases more than $3 \mathrm{~m} / \mathrm{s}$ for an area ratio of 0.26 . Therefore, this issue will increase the power coefficient shown in table 4 .

In the present of four consecutive turbines with a distance of $13 D$ placed in a duct with an area ratio of 0.26, the farm power reached to $12.4 \mathrm{~W}$ and the farm performance factor became 0.944 . This was the best output power of a farm with 2, 3 and 4 consecutive turbines, 3.92 times of a stand-alone turbine's output power. However, as shown in table 3, even though reaching the farm performance factor to 1.0 for a farm with four consecutive turbines and a turbines' distance of $5 \mathrm{D}$, the farm output power became $5.4 \mathrm{~W}$. It 
can be concluded that the existence of a high area ratio duct is far more effective than the distance of turbines.

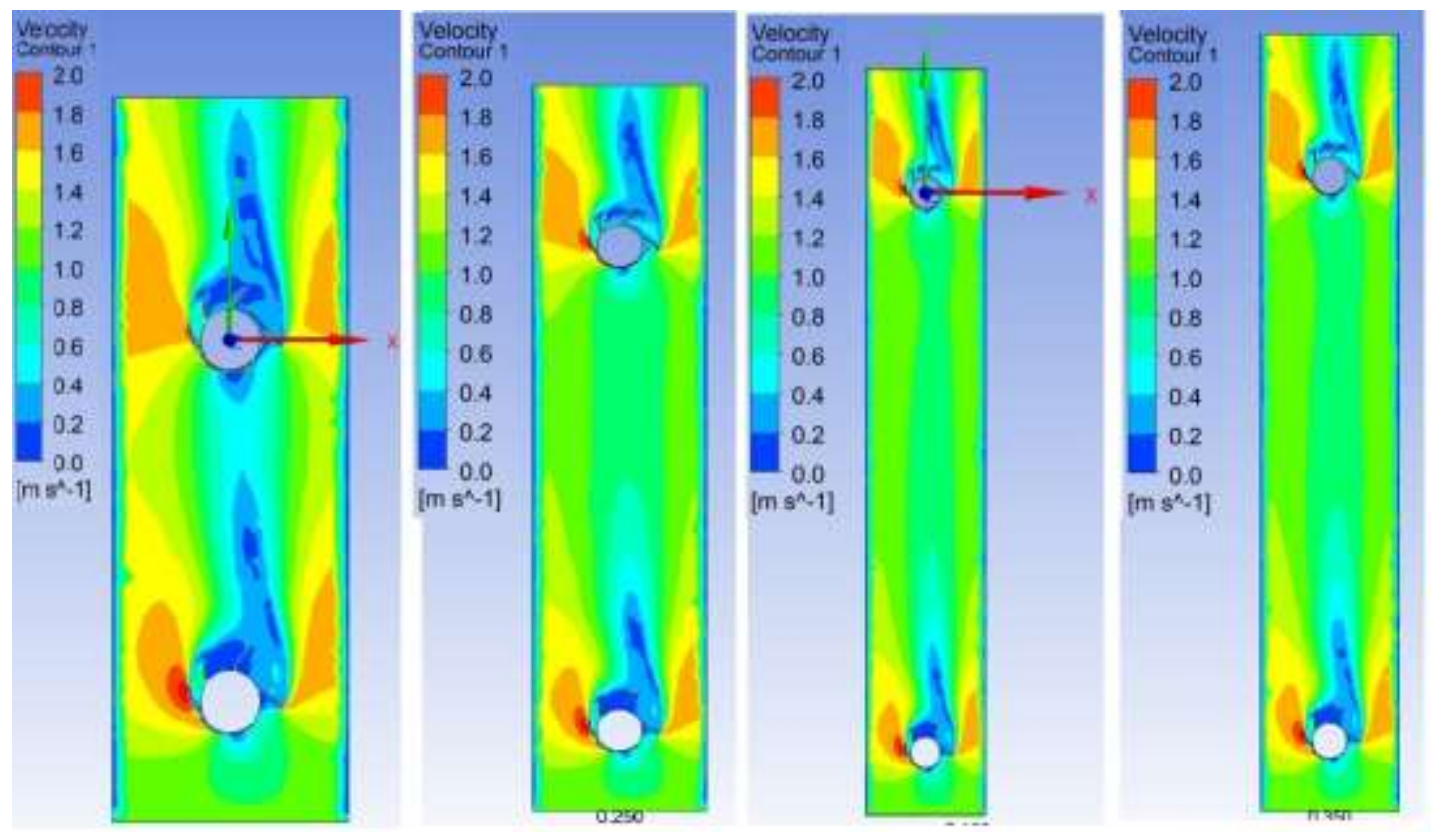

Fig.10. Velocity contours for two consecutive in a duct with area ratio of 0.26 in different distances (from left to right distance between turbines are 5D, 10D, 13D \& 15D, respectively)

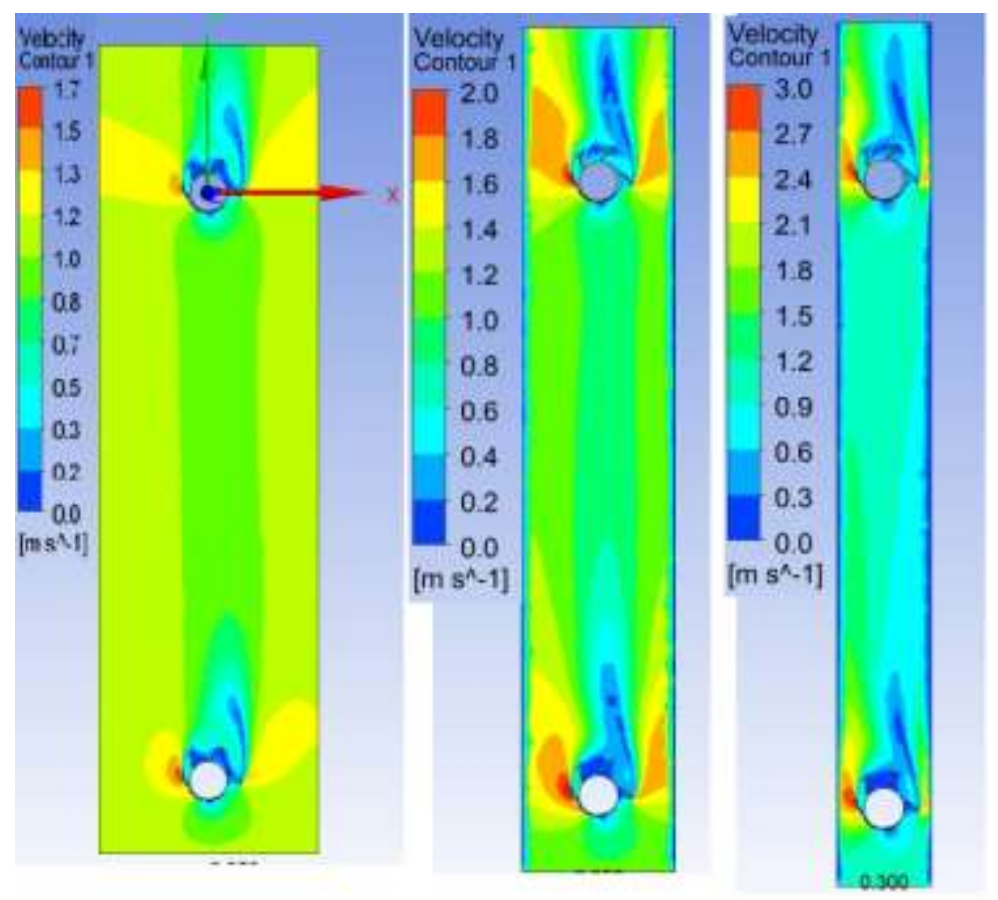


Fig.11. Velocity contours for two consecutive turbines with distance of 13D in different area ratio (from left to right for area ratio of $0.1,0.18$ and 0.26 , respectively)

As shown in table 5, the distance of turbines from each other (the distance is written based on the turbine diameter) and its impact on the farm's output power with 2, 3 and 4 parallel turbines were calculated. On the contrary, for a farm with parallel turbines where the distance of turbines is less, the amount of the farm output power will increase. By two parallel turbines with a distance of $2 D$ in a duct, the power of the farm reached to $4.9 \mathrm{~W}$. In addition, four parallel turbines with a distance of $2 D$ in a duct led to an output power of $10.5 \mathrm{~W}$. Therefore, the output power of a farm with four parallel turbines is more than the output power of a farm with two turbines. In Fig.12, an array of a farm with four parallel turbines and a distance of $2 D$ including its duct's dimensions has been demonstrate schematically.

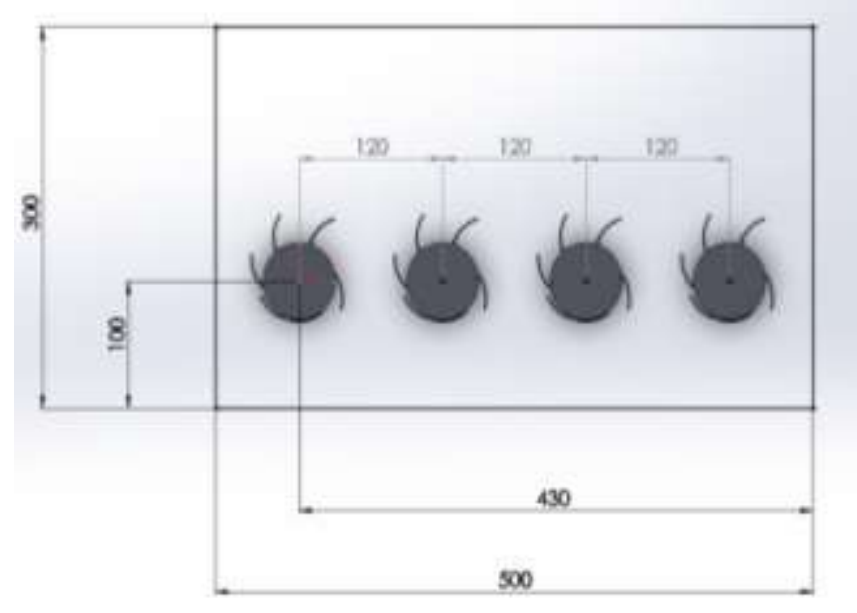

Fig.12. An array of four parallel turbines placed in a duct

Table 5. Effect of the turbine distance on the farm performance factor for 2, $3 \& 4$ parallel turbines

\begin{tabular}{cccc}
\hline Distance & $\mathrm{P}_{2 \text { turbines }}(\mathrm{W})$ & $\mathrm{P}_{3 \text { turbines }}(\mathrm{W})$ & $\mathrm{P}_{4}$ turbines \\
\hline 2D & 4.87 & 7.63 & 10.45 \\
3D & 3.45 & 4.80 & 6.13 \\
4D & 3.04 & 4.12 & 5.19 \\
\hline
\end{tabular}


A triangular arrangement of three turbines was performed for three different angles. Table 6 shows the height and the angle of the triangle. The output power of the farm also listed for each angle. As a result, by increasing the angle of the triangle from $30^{\circ}$ to $60^{\circ}$, the output power of the farm increased by $11 \%$. Fig.13.a shows a triangular arrangement of turbines with angle of $60^{\circ}$.

Table 6. Height and angle between the legs of the triangle for the triangular arrangement

\begin{tabular}{ccc}
\hline Angle & Height $(\mathrm{mm})$ & $\mathrm{P}_{\text {farm }}(\mathrm{W})$ \\
\hline 60 & 156 & 5.27 \\
45 & 217 & 5.00 \\
30 & 336 & 4.74 \\
\hline
\end{tabular}

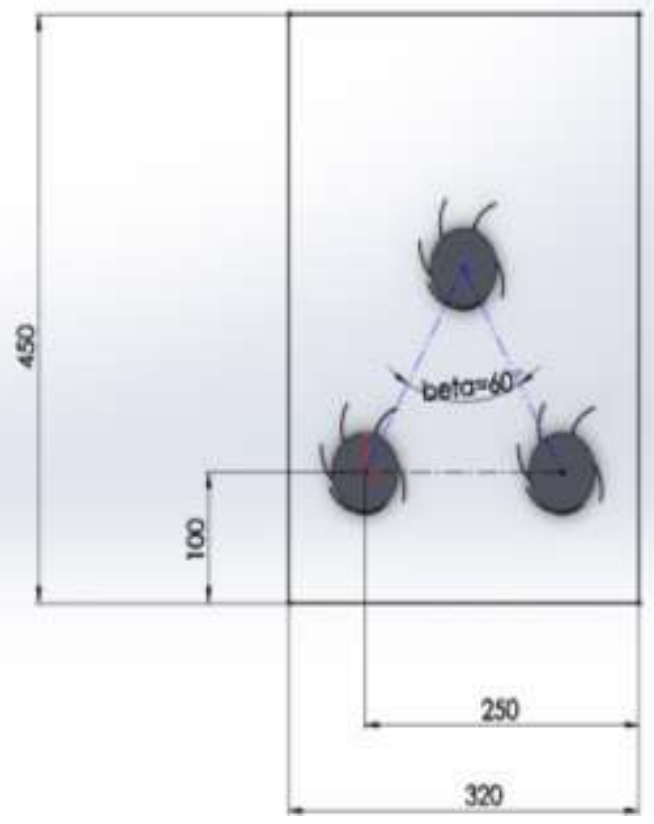

a

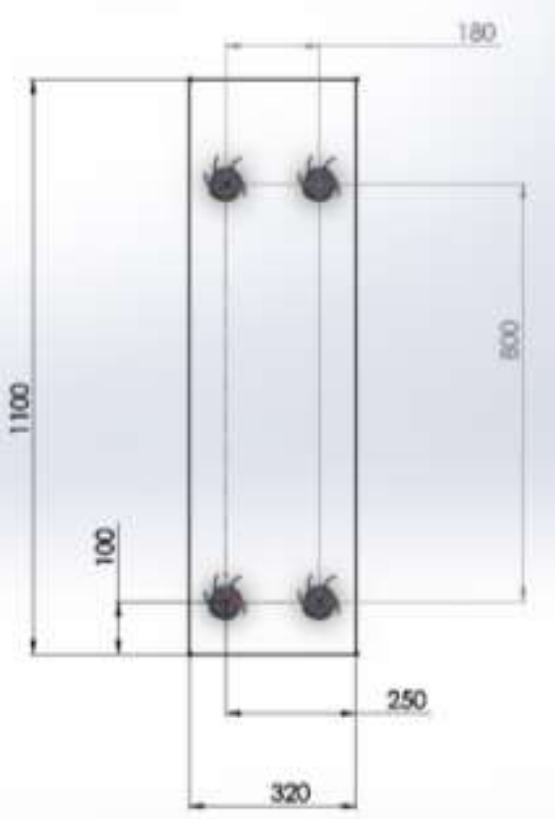

b

Fig.13. a) A triangular arrangement of turbines with angle of $60^{\circ} \mathrm{b}$ ) A rectangular arrangement of turbines 
A rectangular arrangement of four turbines has been shown in Fig. 13.b. For this layout, distances between turbines selected as $3 D$ and $13 D$ in horizontal and vertical directions, respectively. In this situation, the output power of the farm became $6.8 \mathrm{~W}$. Therefore, the rectangular turbine is recommended.

\section{Conclusions}

In the present paper, a Hunter tidal turbine was experimentally and numerically studied. In the first step, a model of Hunter turbine was manufactured and tested in an established test rig. Measured data was used to verify the 3D steady Reynolds-Averaged Navier-Stokes (RANS) equations solving around the turbine done by CFD. The maximum devotion for the flow confident was reasonable. In addition, effects of duct, neighbor turbines distance and turbines layout on the turbine's power coefficient were considered. The results showed that the power coefficient of a turbine increased for ducts with more area ratios. It was also observed that in a four-turbine farm, the output power is maximum for a distance between neighbor turbines of $13 D$. However, the existence of ducts with higher area ratios is far more effective than the distance of turbines on increasing of farm's power output. Finally, two farms with triangular and rectangular arrangements were investigated. Generally, the rectangular arrangement was recommended as a reasonable layout.

For the future works, it is proposed to investigate the vertical position of turbine in a tidal or stream flow. In addition, due to long blades of high capacity prototype turbines, focusing on the material strength of Hunter turbine's blades is seemly favorable.

\section{Acknowledgments}

The authors gratefully acknowledge the financial support of INSF (Iran National Science Foundation).

\section{References}


[1] Blunden LS, Bahaj AS. Tidal energy resource assessment for tidal stream generators. Proceedings of the Institution of Mechanical Engineers Part A Journal of Power and Energy 2007; 221(10):137e46.

[2] World Energy Assessment (WEA). UNDP, United Nations Department of Economic and Social Affairs. New York: World Energy Council; 2000.

[3] Derakhshan S, Kasaeian N. Optimization, Numerical and Experimental Study of a Propeller Pump as Turbine. ASME J. Energy ResourTechnol 2013; 136(1): 012005.

[4] Smith F. Sustainability at the cutting edge, emerging technologies for low energy building. $2^{\text {nd }}$ ed. Amsterdam: Elsevier; 2007.

[5] Fecarotta, O., Carravetta, A., Ramos, H. M., \& Martino, R. (2016). An improved affinity model to enhance variable operating strategy for pumps used as turbines. Journal of Hydraulic Research, 1-10.

[6] Carravetta, A., Fecarotta, O., Martino, R., \& Antipodi, L. (2014). PAT efficiency variation with design parameters. Procedia Engineering, 70, 285-291.

[7] Vieira, F.; Ramos, H.M. Hybrid solution and pump-storage optimization in water supply system efficiency: A case study. Energy Policy 2008, 36, 4142-4148.

[8] Fecarotta, O., Aricò, C., Carravetta, A., Martino, R., \& Ramos, H. M. (2015). Hydropower potential in water distribution networks: Pressure control by PATs. Water Resources Management, 29(3), 699-714.

[9] Carravetta, A., Del Giudice, G., Fecarotta, O., \& Ramos, H. M. (2013). Pump as turbine (PAT) design in water distribution network by system effectiveness. Water, 5(3), 1211-1225.

[10] Carravetta, A., Fecarotta, O., Del Giudice, G., \& Ramos, H. (2014). Energy recovery in water systems by PATs: A comparisons among the different installation schemes. Procedia Engineering, 70, 275-284. 
[11] Derakhshan, S., and Nourbakhsh, A., 2008, "Experimental Study of Characteristic Curves of Centrifugal Pumps Working as Turbines in Different Specific Speeds,” Exp. Thermal Fluid Sci., 32, pp. 800-807.

[12] Derakhshan S, Nourbakhsh A. Theoretical, numerical and experimental investigation of centrifugal pumps in reverse Operation. Experimental Thermal and Fluid, Science 2008; 32(5):1620e7.

[13] Yang, S.-S., Derakhshan, Sh., and Kong, F., 2012, “Theoretical, Numerical and Experimental Prediction of Pump as Turbine Performance," Renewable Energy, 48, pp. 507-513.

[14] Bozorgi, A., Javidpour, E., Riasi, A., and Nourbakhsh, A., 2013, "Numerical and Experimental Study of Using Axial Pump as Turbine in Pico Hydropower Plants," Renewable Energy, 53, pp. $258-264$. [15] Derakhshan, S., and Mostafavi, A., 2011, “Optimization of GAMM Francis Turbine Runner," World Acad. Sci. Eng. Technol., 59, pp. 717-723.

[16] Yassi, Y.; Hashemloo, S. Improvement of the efficiency of the Agnew micro hydro turbine at part loads due to installing guide vanes mechanism. Energy Convers. Manag. 2010, 51, 1970-1975

[17] Sammartano, V.; Aricò, C.; Carravetta, A.; Fecarotta, O.; Tucciarelli, T. Banki-michell optimal design by computational fluid dynamics testing and hydrodynamic analysis. Energies 2013, 6, 23622385.

[18] Reihani A., Ojaghi A., Derakhshan S., Beigzadeh B., Shaft fatigue life and efficiency improvement of a micro cross flow turbine, Engineering Solid Mechanics 2014, 2, 1-14.

[19] Buccino, M.; Banfi, D.; Vicinanza, D.; Calabrese, M.; Del Giudice, G.; Carravetta, A. Non breaking wave forces at the front face of seawave slotcone generators. Energies 2012, 5, 4779-4803.

[20] Vicinanza, D.; Ciardulli, F.; Buccino, M.; Calabrese, M.; Koefed, J. Wave loadings acting on an innovative breakwater for energy production. J. Coast. Res. 2011, 64, 608-612.

[21] Bryden, G.; Couch, S. ME1-marine energy extraction: Tidal resource analysis. Renew. Energy 2006, 31, 133-139. 
[22] Garrett, Chris, and Patrick Cummins. "The efficiency of a turbine in a tidal channel." Journal of fluid mechanics 588 (2007): 243-251.

[23] Khan, M. J., et al. "Hydrokinetic energy conversion systems and assessment of horizontal and vertical axis turbines for river and tidal applications: A technology status review." Applied Energy 86.10 (2009): 1823-1835.

[24] Yang B., Lawn C. Fluid dynamic performance of a vertical axis for tidal currents. Renewable energy 2011; 36(12):3355-3366.

[25] Yang B., Lawn C. Three Dimensional effects on the performance of a vertical axis tidal turbine. Ocean engineering 2013; 58:1-10.

[26] Vennell R. Realizing the potential of tidal currents and the performance factor of turbine farms in a channel. Renewable Energy 2012; 47:95-102

[27] Li Y. On the definition of the power coefficient of tidal current turbines and performance factor of tidal current turbine farms. Renewable Energy 2014; 68:868-875.

[28] Garrett C., Cummins P. The performance factor of a turbine in a tidal channel. J Fluid Mech 2007; 588:243e51.

[29] Whelan JI., Graham JMR., Peiro J. A free-surface and blockage correction for tidal turbines. J Fluid Mech 2009; 624:281e91.

[30] Derakhshan S., Tavaziani A., Kasaeian N. Numerical Shape Optimization of a Wind Turbine Blades Using Artificial Bee Colony Algorithm. ASME J. Energy ResourTechnol 2015; 137: 051210-1-12.

[31] Yang B. A new blade design scheme for reversible axial flow fan and research on the combined cascades. Ph.D. thesis; Shanghai Jiaotong University: 2001. 


\section{Figures Caption:}

Fig.2. Laboratory model of vertical axis tidal turbine

Fig.2. Turbine position in open channel test rig

Fig.3. a) Computational domain of turbine b) Unstructured grids of turbine

Fig.4. Comparison of the experimental and the numerical results for the power coefficients

Fig.5. Velocity counters in different blade angles at $\varphi=0.45$

Fig.6. Pressure counters in different blade angles at $\varphi=0.45$

Fig.7. Stream lines in different blade angles at $\varphi=0.45$

Fig.8. a) dimension of duct and the position of turbine (case No.3) b) computational domain around the duct

Fig.9. A four array of consecutive turbines

Fig.10. Velocity contours for two consecutive in a duct with area ratio of 0.26 in different distances (from left to right distance between turbines are 5D, 10D, 13D \& 15D, respectively)

Fig.11. Velocity contours for two consecutive turbines with distance of 13D in different area ratio (from left to right for area ratio of $0.1,0.18$ and 0.26 , respectively)

Fig.12. An array of four parallel turbines placed in a duct

Fig.13. a) A triangular arrangement of turbines with angle of $60^{\circ}$ b) A rectangular arrangement of turbines

\section{Tables Caption:}


Table 1. Boundary conditions of the computational domain

Table 2. Cross section of ducts and corresponding power of coefficients

Table 3. Effect of turbine distance on the farm performance factor for $2,3 \& 4$ consecutive turbines at the area ratio of 0.26

Table 4. Effect of area ratio on the farm performance factor for $2,3 \& 4$ consecutive turbines at the distance of 13D

Table 5. Effect of the turbine distance on the farm performance factor for 2, $3 \& 4$ parallel turbines

Table 6. Height and angle between the legs of the triangle for the triangular arrangement 